\title{
A Framework for Interaction and Cognitive Engagement in Connectivist Learning Contexts $^{1}$
}
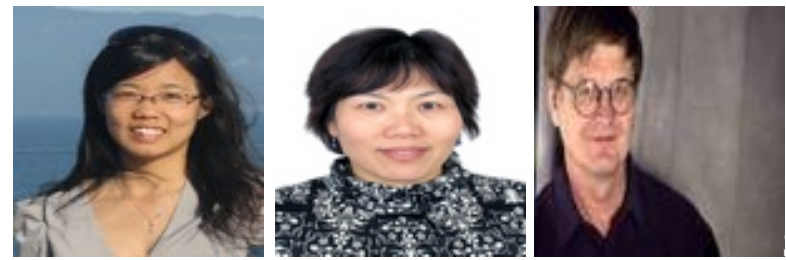

Zhijun Wang ${ }^{1}$, Li Chen ${ }^{1}$, and Terry Anderson ${ }^{2}$

1Beijing Normal University, China, ${ }^{2}$ Athabasca University, Canada

\section{Abstract}

Interaction has always been highly valued in education, especially in distance education (Moore, 1989; Anderson, 2003; Chen, 2004a; Woo \& Reeves, 2007; Wang, 2013; Conrad, in press). It has been associated with motivation (Mahle, 2011; Wen-chi, et al., 2011), persistence (Tello, 2007; J oo, Lim, \& Kim, 2011), deep learning (Offir, et al., 2008) and other components of effective learning. With the development of interactive technologies, and related connectivism learning theories (Siemens, 2005a; Downes, 2005), interaction theory has expanded to include interactions not only with human actors, but also with machines and digital artifacts. This paper explores the characteristics and principles of connectivist learning in an increasingly open and connected age. A theory building methodology is used to create a new theoretical model which we hope can be used by researchers and practitioners to examine and support multiple types of effective educational interactions. Inspired by the hierarchical model for instructional interaction (HMI) (Chen, 2004b) in distance learning, a framework for interaction and cognitive engagement in connectivist learning contexts has been constructed. Based on cognitive engagement theories, the interaction of connectivist learning is divided into four levels: operation interaction, wayfinding interaction, sensemaking interaction, and innovation interaction. Connectivist learning is thus a networking and recursive process of these four levels of interaction.

Keywords: Connectivist learning; interaction; connectivism; cognitive engagement

${ }^{1}$ The study reported in this paper is supported by the China Scholarship Council (CSC). ${ }^{*}$ Corresponding author, Research Center for Distance Education Beijing NormalUniversity 


\section{Introduction}

A new network-based pedagogy termed "connectivism" and the associated term "connected knowledge" was first developed by Siemens (2005a, 2005b, 2006) and Downes (2006) as a means to understand and explore learning in a networked digital age. With the continuing development of interactive technologies and connectivism learning theory, e-learning has been extended from early forms of print content delivered by email, to social constructivist learning, and, most recently, to connectivist learning. Connectivist learning is similar to ideas described as connected learning (Anderson \& Dron, 2011), social networked learning (Siemens \& Conole, 2011; Fonseca, 2011), and network connected teaching (Fadell et al., 2013).

The most widely discussed application of connectivist learning has been developed within some of the earliest MOOCs. These first MOOCs, known as cMOOCs or connectivist MOOCs, were developed and used to validate the ideas of connectivism developed by George Siemens and Stephen Downes. The aim of this particular model of MOOCs was to explore new ways of teaching and learning relevant to and afforded by a social and network enhanced digital age. In particular, these early MOOCs stressed the importance of learners developing their individual, personal learning networks and of creating, sharing, and enhancing net-based learning artifacts. They are quite different from the later MOOCs, referred to as XMOOCs (Malliga, 2013) which focus more on the distribution of content and ignore the aforementioned key features of cMOOCs, in that they inherently involve interaction and network construction and, especially, learnerlearner interaction focused on content creation and sharing.

Interaction has long been valued in distance education. Connectivist pedagogies stress that learning is a type of interaction centred on the learners' networked knowledge creation and growth (Downes, 2012, p. 63; Siemens, 2011, p. 85). Interaction both with other humans and with network resources is critical for connection building and network formulation. Siemens (2011) observed that "social interactions are vital to how participants made sense of course content and how they orient themselves spatially" ( $p$. 157). Downes (2012) also argued that "interaction not only promotes human contact, it provides human content... it creates a deep layer of learning content that no developer could ever hope to create" (p. 48). The same conclusion can be made from the 'model of learner-technology relationship in MOOCs' created by Siemens (2011, p. 85), which displays that interaction is as important as creation in connectivist learning.

\section{Research Questions}

Interaction is thus claimed to be a critical component and activity in connectivist learning, but little research has attempted to clarify its role in learning from a theoretical viewpoint. The research question that drives this theoretical research is, what are the characteristics and principles of interaction in a complex connectivist learning process? Can they be clearly revealed when viewed from a systematic view focused on interaction? This article provides a systematic interaction framework for 
connectivist learning, which reveals the characteristics and principles of learners' interactions so as to guide interaction design and evaluation in connectivist learning designs and implementations. This theoretical and model-building research is designed to bridge the gap between connectivist pedagogical ideas and learning practice, and to provide more specific solutions and guidance to connectivist learning designers, facilitators, and participants.

\section{Literature Review}

\section{Connectivism and its Practice Forms}

Connectivism is a relatively recent pedagogical theory, but it has proven to be both timely and useful. The seminal 2005 article by George Siemens was mentioned 669 times in scholarly publications indexed by Google Scholar in 2012, and by 2013 it had been referenced 1,603 times. The central tenets of connectivism are defined in eight principles (refer to Siemens, 2005a). These principles have shaped the development of connectivism learning designs, activities, and courses. The ideas of connectivism have been developed and contested in a series of articles, special journal issues, blog posts, presentations, workshops, and cMOOCs, including CCK08, CCK09, and CCK11. Although acclaimed by some, connectivism has also been criticized by many others (notably, Verhagen, 2006; Kop, Hill, 2008; Clarà \& Barberà, 2013). Verhagen argued that Siemens' ideas are, at best, pedagogical views, and certainly do not stand up to proper notions of the necessity for theory refutation. For a more detailed discussion of connectivism as a theory and the use of models to develop theoretical ideas, please see the overview by Kop and Hill (2008). Clarà and Barberà (2013) also pointed out three problems of connectivism as a learning theory. One of them is underconceptualization of interaction, which, on the other hand, helps us highlight the importance of interaction in connectivist learning.

Though both social constructivism and connectivism describe learning as a social process where learning occurs through social interaction, connnectivist learning occurs not just through social interaction, but also through interaction with and between networked nodes (people, media, places), because knowledge is distributed across a network of connections (Downes, 2007). Thus, in social constructivism, a network is social media for interaction, while in connectivism a network is an extension of mind. Connectivist learning therefore consists of the ability to construct and traverse those networks (Downes, 2007). Siemens' (2009) chart comparing connectivism with other theories is useful in distinguishing connectivism from other prominent learning theories.

Connectivist theory has inspired activities in different practice forms and designs based upon different purposes and understanding of connectivism by both practitioners and researchers. This study divided these activities into three forms. The first practice form 
is simple connectivist learning; the purpose of this kind of learning is to find ways to access information so as to achieve a particular answer or solution, such as pupils finding the solution to a complex mathematical problem using a search engine on a mobile phone. This focus on the process of learning is consistent with the famous claim of connectivism that "the pipe is more important than the content within the pipe" (Siemens, 2005a). The second practice form is social networked learning. The main purpose of this kind of learning is to gather people with some common interest to build a network for knowledge sharing and connection, such as Cloudworks (Conole, Galley, \& Culver, 2010) at the Open University, the Landing (Anderson, et al., 2013) at Athabasca University, and the Learning Cell (Cheng, Yu, \& Yang, 2009) at Beijing Normal University. The third practice form is complex connectivist learning in which students use and develop their own resources to prompt connection building and network formulation that is distributed in complex learning environments through knowledge creation, decision making related to complex problems, and the development of technological and pedagogical innovations, such as cMOOCs. Each of these forms is built and sustained upon interaction, to which we turn next.

\section{Research Related to Interaction in Distance Education}

"Interactions are reciprocal events that require at least two objects and two actions" (Wagner, 1994, p. 8). This definition of interaction includes the possibility of "reciprocal events" between humans and machines, which is an important construct in connectivist learning, thus it is used in this paper. The interaction discussed in this paper is one with pedagogical or educational intent and value.

Interaction has been a key concept and highly valued by most distance education theorists since the earliest correspondence generations of distance education (Taylor, 2001). The guided didactic conversation (Holmburge, 1981) and continuity of concern for students (Sewart et al., 1983) placed interaction between students and teachers at the core of distance education practice and theory. Moore's three types of interaction (1989) formed the first systematic and main theoretical framework for most research related to interaction. With the development and use of two-way communication technologies, interaction became the main research topic in distance education, and a number of theories related to interaction were created over the next two decades. These included Moore's theory of transactional distance (1993), the reintegration of the teaching acts (Keegan, 1993), modes of interaction in distance education (Anderson \& Garrison, 1998), and interaction-based models of elearning (Anderson, 2003). A great deal of research looked at how to design interaction more efficiently (Hirumi, 2002; Anderson, 2003; Ally, 2004; Chen, 2004b). From the beginning of the 21st century, with the rapid development of social media and Web 2.0 technology, social interaction has become a much discussed topic in online, campus, and blended learning research. Most research focused on interaction design, analysis, evaluation, enhanced strategies and their influence on learners' satisfaction, and learning performances in different social interaction contexts. Among these studies of interaction design, researchers were focused on interactive functions of course management systems (Chou, 2010) and interaction design of courses (Hirumi, 2006; Dunlap et al., 2007; Nandi, 2013). 
Different interaction design methods have been proposed with various perspectives, but So (2010) commented that the research on interaction should involve "tight coupling the pedagogical methods and technological affordance" (p. 256) to ensure rigor in the research on interaction. Although numerous studies have been published on the role of interaction in cognitive behaviour and social constructivist pedagogy, no analytic attention has been paid to the interaction in connectivist learning from a systematic or structured viewpoint.

\section{Types of Interaction in Connectivist Learning}

Distance education developed from cognitive behavioural pedagogical roots and later to social constructivist pedagogy and connectivism pedagogy (Anderson \& Dron, 2011), which coincided with developments of interactive affordances of networked, digital technologies. Using cognitive behavioural pedagogy, Moore (1989) first proposed three types of interaction (student-teacher, student-student, student-content) in distance education, followed by the addition of student-interface interaction as a fourth interaction (Hillman, et al., 1994). As intelligent technology developed, three other possible forms of interaction (teacher-teacher, teacher-content, and content-content) were added to the framework (Anderson \& Garrison, 1998). In social constructivist pedagogy the interaction capacity of Web 2.0 and social technologies increased the capacity and varieties while decreasing the costs of interaction for social learning. Dron (2007) added four types of interaction to the framework of interactions (group-content, group-group, learner-group, and teacher-group). Connectivist pedagogy stresses the development and nurturing of networks to be a major component of learning. The interaction affordances of a strong social network environment have extended the interaction possibilities (Ostashewski \& Reid, 2010). Networks, sets, and collectives are "emerging catalytic components" (Anderson \& Dron, 2007, p. 197) of learner interactions with others as they develop their personal networks. Finally, interactions with and learning from sets of people or objects form yet another mode of interaction (Dron \&Anderson, in press).

As discussed above, the types of interaction are extended with the development of technology in different distance learning pedagogies. Interaction is opened (beyond the class) and extended (to objects and people aggregated in groups, networks, and sets) in connectivist learning, including almost all of these types of interaction, so interaction in connectivist learning is the most complicated type, and deserves extra attention. The participants have increased choice and opportunity to interact with others according to their network literacy (Belshaw, 2013), the networks they belong to, and the sets they curate and with which they interact. Interactions extend from individuals to groups and networks, from closed to open, from small group to massive possibilities. This affords opportunities for network development, potential to develop both strong and weak links (Granovetter, 1973), and opportunity to jump across or cross boundaries. Perhaps even more important, if emergent, is the increase in the "adjacent possible" (Kauffman, 2000; Dron, 2013), whereby new and often unanticipated connections arise and can be exploited for learning potential. At the same time, such an expansion of interaction possibilities creates the need for more sophisticated conceptual models for both 
understanding and exploitation of the learning potential. However, the principles of interaction and the technologies and pedagogies with which they are most closely matched should be explored first. But it is challenging to have a sufficiently in-depth understanding of interaction merely from the classification of different interactions based on their actors within Moore's framework. So, other research perspectives are sought to reveal the principles of interaction in connectivist learning.

\section{The Strategy of Dividing Interaction into Different Levels}

Besides analysing interaction based on key actors, another strategy that researchers have adopted is to segment interaction into different levels depending on actors or activities involved. Hirumi (2002) divided the interaction of online learning into three levels, learner-self, learner-resource (human and non-human), and a meta level learnerinstruction interaction which guides the previous two types. Chen (2004b) divided interaction into operation interaction, information interaction, and concept interaction, from simple to complex and concrete to abstract. Ally (2004) divided interaction in online learning into five levels (from learner-content to learner-interface; learnersupport, learner-learner, and learner-context). The common purpose of these three studies was to explain how learning occurs from various interaction perspectives by dividing the interaction into different levels and constructing corresponding frameworks to guide interaction activity design. Compared with other studies focusing on one type of interaction, these three studies paid more attention to the relationship of interaction and learning, which is useful in providing an in-depth and systematic understanding of interaction and to build theories of interaction. Thus, the strategy of dividing interaction into different levels or taxonomies is adapted and extended in this study. We also attempted to build a framework to guide interaction activity designs. Among these three frameworks, Chen's, which is based on the relationship of interaction with meaningful and deep learning, rather than those based on the actors, has proven to be the most useful as a launching framework for this research, which will be discussed later.

\section{Research Method: Theory Building}

The methodology used in this study is theory building in applied disciplines (Lynham, 2002). This has been described as "the purposeful process or recurring cycle by which coherent descriptions, explanations, and representations of observed or experienced phenomena are generated, verified, and refined" (Lynham, 2000, p. 161). Although different researchers have advocated different theory-building processes, Lynham (2002) proposed a five-phase method of theory-building. These are theory building, conceptual development, operationalization, confirmation or disconfirmation, application, and continuous refinement and development (of the theory) as a recursive system (Lynham, 2002). This method consists of two components, described as theorizing-to-practice and practice-to-theorizing. Theorizing-to-practice is a qualitative method, while practice-to-theorizing is quantitative. Each produces a distinct in-process 
output and results in a rigorous, trustworthy, and relevant model and theory for improved action (Lynham, 2002). This research focused on a theoretical framework which, hopefully, provides an explanation of the issue, problem, or phenomenon of focus.

This study analyzes interaction in connectivist learning as a system, building a framework to explain the characteristics and principles of interaction in connectivist learning. The theorizing-to-practice component was chosen as the research strategy, because it is well suited to the applied nature of the behavioural and human sciences (Lynham, 2002) including education. We note that, similar to earlier conceptual models such as the community of inquiry model (Garrison \& Anderson, 2003), Laurillard's conversational framework (Laurillard, 2000) or Salmon's five stage e-learning model (Salmon, 2000), the early construction of a guiding graphical model has stimulated both research and practice and led to later enhancements. We hope our work stimulates similar extension, revision, and validation.

\section{Conceptual Framework for Interaction in Connectivist Learning}

\section{Hierarchical Model for Instructional Interaction}

Chen (2004a) proposed the concept of instructional interaction, which explains how distance learning occurs from an interaction perspective and delineates the role of different kinds of interaction in distance education. Chen (2004b) built a hierarchical model for instructional interaction (HMI) (Figure 1) in a distance learning context, based on Laurillard's conversation framework. According to HMI, interaction in distance learning contexts can be divided into three levels, from concrete to abstract and from low to high levels. The most concrete level is operation interaction, in which the learner operates different media and is interacting with the media interface. Due to the extensive use of technology in distance education, the operation interaction is more complicated and is both the foundation and condition of online learning. The second level is information interaction, which includes learner-teacher, learner-learner, and learner-content interactions. The third level is the most abstract one, referred to as concept interaction, which is the interaction of learners' old concepts with new ones. These three levels of interaction can occur simultaneously and recursively. The operation interaction is the foundation of information interaction, while information interaction is the foundation of concept interaction (Chen, 2004b). The higher the level, the more critical it is to the achievement of learning objectives. Chen argued that only concept interaction leads to meaningful learning. HMI, however, formulated in a constructivism context, reveals the basic interaction principles of distance and online learning (Wang, 2013), so it continues to serve as a base for our current understanding of interaction. HMII provided a guide or heuristic that was used to analyse interaction 
in constructivist learning, thus the HMI was used to build an additional theoretical framework of interaction in this study.

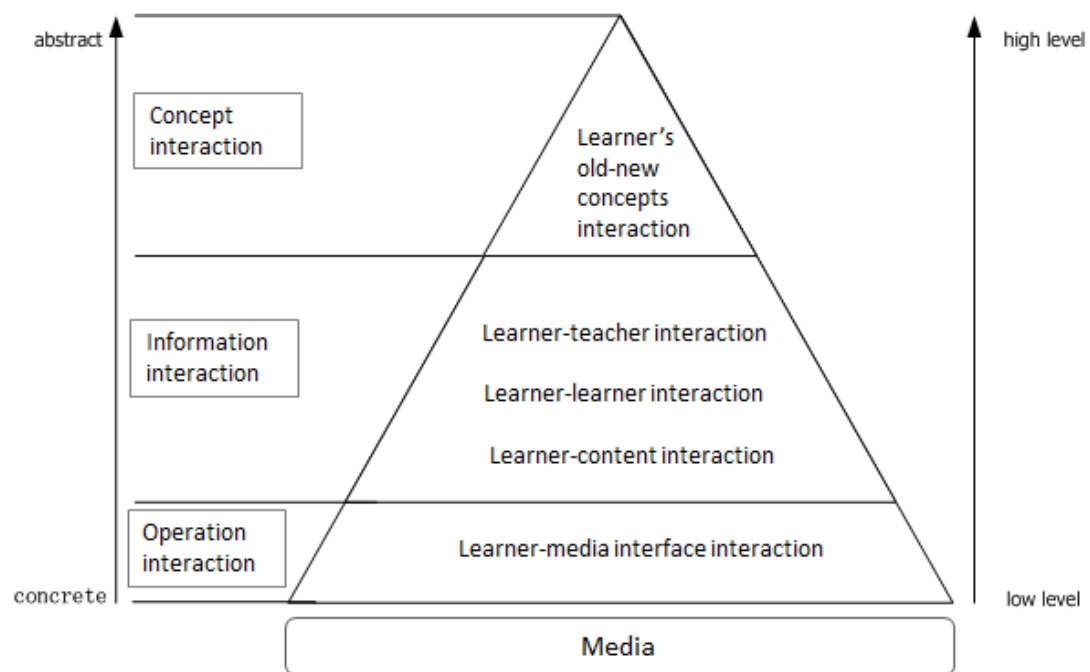

Figure 1. Hierarchical model for instructional interaction (HMII) (Chen, 2004b).

\section{Conceptual Development Process}

Connectivist pedagogy is based on creating and sustaining networks linking humans to other humans and to non-human resources because knowledge resides in networks of humans and non-human appliances (Siemens, 2005; Bell, 2011). Learners create their interaction spaces in a type of personal learning environment (PLE) (Martindale \& Dowdy, 2010) by using different media (especially social media) to create, access, and build networks with each individual at the centre of their own network. The mastery of the operation of different media and technologies, such as blogs, wikis, micro-blogging, and social media websites, enables learners to participate in connectivist learning. So operation interaction, including human-computer interaction and human-interface interaction, still serves as a basis and precondition for other interactions (Chen, 2004b) and indeed becomes even more complex in connectivist learning contexts.

The information interaction level of HMI is complicated in connectivist learning. Compared to traditional education (delivered on campus or at a distance) with wellstructured content and defined learning resources, activities, and fixed technological platforms, connectivist learning takes place in complex, information-loaded environments and stresses emergence (Kay, 2006). In this environment, content is distributed on networks amongst individuals surrounded by fragmented information which encourages rather than suppresses the emergence of creativity and deep learning in the distributed and complex environments that embrace unplanned interactions. It is important for participants to learn how to orientate themselves in such complex information contexts so as to make the information coherent and understandable (Siemens, 2011). Siemens (2011) proposed two means of orientation in complex online learning environments - wayfinding and sensemaking; he acknowledged that 
"wayfinding detail shows that people orient themselves spatially through the use of symbols, landmarks, and environmental cues" (p. 48) and "sensemaking is an activity that individuals engage in daily in response to uncertainty, complex topics, or in changing settings (p. 39)". Learners interact constantly with networks to navigate in complex environments and to filter, integrate, and extract information to develop their understanding of that information. Thus, this level consists of both kinds of interaction, wayfinding and sensemaking interaction.

The third level of HMII is concept interaction. It requires and stimulates the deepest cognitive engagement. In connectivist learning, the deepest cognitive engagement is creation. The deepest level of interaction in connectivist learning is innovation interaction, which is related to, but deeper and more applied than, concept interaction. Moreover, the concept interaction of HMI is included in both the information (wayfinding and sensemaking) and the final "innovation interaction". Innovation interaction is a process of knowledge creation and growth (Downes, 2012). It includes the presentation and expression of new ideas, solutions, theories, and models through creation of new learning artifacts individually or collaboratively for further connection building. It is mainly combined with learner-content interaction, but in collaborative and formal learning environments, learner-learner and learner-teacher interactions are also important.

Figure 2 demonstrates the above deductive process of dividing interactions in connectivist learning into four different levels: operation interaction, wayfinding interaction, sensemaking interaction, and innovation interaction.

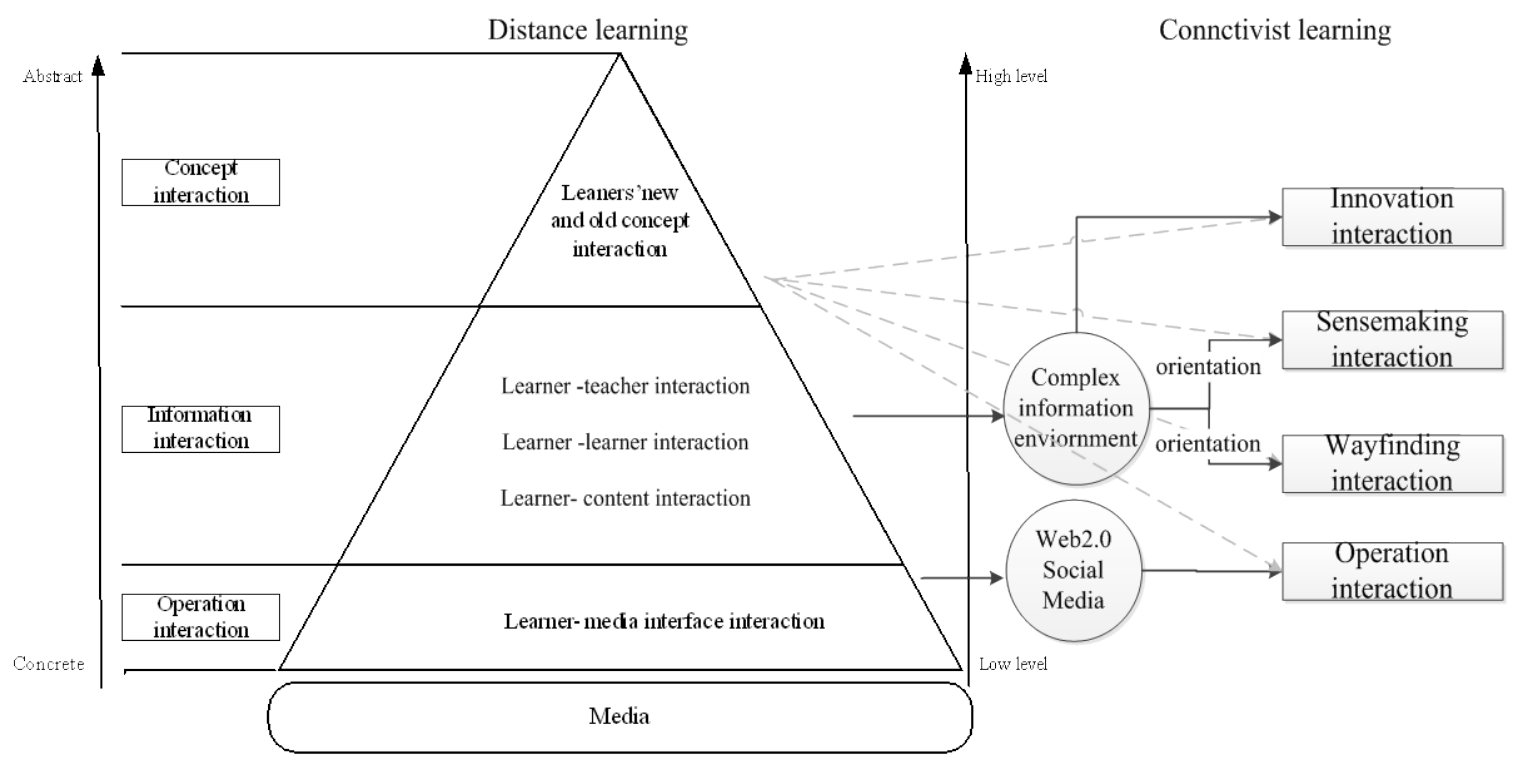

Figure 2. Conceptual development of interaction in connectivist learning.

To help us to understand the cognitive engagement at these four levels of interaction, the conceptual framework for connectivist learning is analysed and compared using 
Bloom's revised taxonomy. Bloom's cognitive taxonomy (1956) was revised and updated in 2000 by changing the nouns to verbs and elevating creation to the highest level (Anderson, et al., 2000). The revised taxonomy moves from remembering to understanding, applying, analysing, evaluating, and creating as cognitive processes (Anderson, et al., 2000). During operation interaction the learners merely practice and remember how to operate various media to build their own learning spaces. In wayfinding interaction, learners have to master the ways to navigate in a complex information environment and connect with different human and non-human resources, so they have to reach higher levels of understanding, applying, and evaluating information and connection formed in this process. Sensemaking is a patternrecognition process, so the top five categories of the cognitive taxonomy are each involved in it, especially applying, analysing, and evaluating. Innovation interaction focuses on the expression of ideas, models, or theory by artifact creation and innovation to enhance and build new social, technological, and informational connections. It thus engages learners at the deepest, creation level of Bloom's revised taxonomy.

These four levels of interaction are not independent. Changes in one influence the process of another. Only when innovation interaction happens have the learners reached the deepest level of connectivist learning. Figure 3 shows the final conceptual framework constructed in this research.

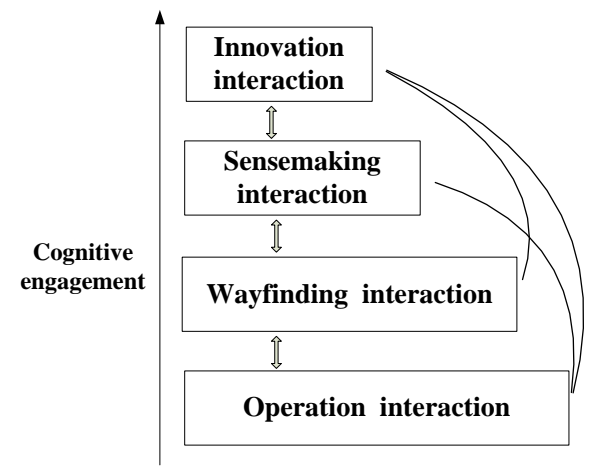

Figure 3. Conceptual framework of interaction for connectivist learning and cognitive engagement.

\section{Operationalization of the Conceptual Framework}

Lynham (2002) stated that "one of the challenges of theory-building research in applied disciplines is making the logic used to build the theory explicit and accessible to the user of the developed theory" (p. 221). Based on a literature review of connectivism, personal reflections on wayfinding, sensemaking, and artifact creation experienced in $\mathrm{CMOOC}$ learning experiences, and discussions with connectivist learning researchers, the resulting operationalized conceptual framework can be visualized as Figure 4. It is called a framework for interaction and cognitive engagement in connectivist learning. 


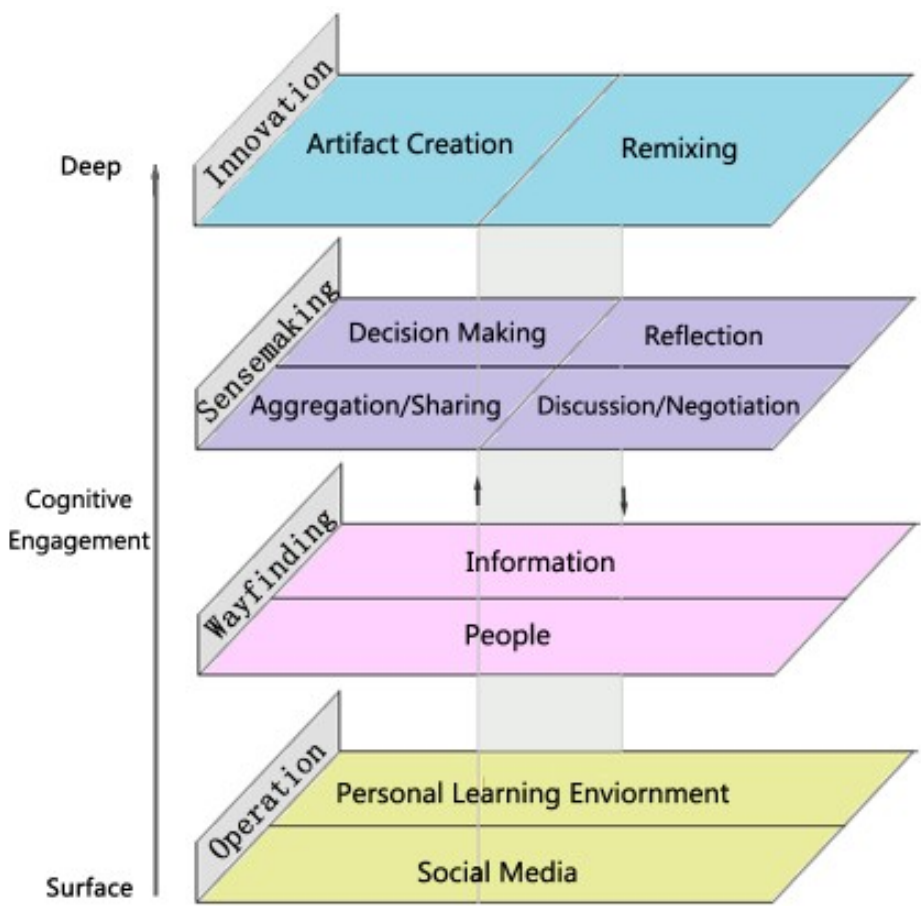

Figure 4. Framework for interaction and cognitive engagement in connectivist learning.

\section{Operation Interaction}

"Technology is an enabler of new opportunities" (Siemens, 2009, p. 2). The purpose of operation interaction is to build interaction spaces or a PLE with different technologies for connecting with different knowledge and opportunities. Compared to traditional online learning in learning management systems, PLE construction is much more open, interactive, controlled by individual learners, and has widespread social and networking connection capabilities. These characteristics are essential for the diversity and expandability of PLE and the ability for learners to bridge learning across multiple learning and living contexts. So learners strive to integrate other social and networkbased media into their PLEs. Different technologies have different affordance in supporting information aggregation, social connection, content generation, and cocreation (Sun, 2013). Learners reside in different technology spaces based on their habits and experiences of operating these media. While learners connect with different technologies in operation interaction, it also provides the possibility to connect with different groups of people and information, and to change their sensemaking behaviours. This can explain why learners are usually asked to register in a variety of social networks and they learn how to follow, aggregate, and filter content from these social network technologies at the beginning of a connectivist learning experience (Downes, 2011). Operational interaction is a process of learners connecting with different technologies through learner-interface interaction to support their further learning. A collective distributed technological network is formed in this process. 


\section{Wayfinding Interaction}

"Learning is a process of connecting specialized nodes or information sources" (Siemens, 2005). Wayfinding interaction is used to connect the pipeline for knowledge flow (Siemens, 2006, p. 79), including the connection of information and people (in groups, sets, or networks). The learning environment of connectivist learning is more complex than any other kind of learning, so it is important for the learners to judge which information is important and valuable for them so as to navigate in this environment. "The capacity for connection forming, becoming aware (of others and knowledge), and sustaining exchanges lies at the heart of knowledge exchange today" (Siemens, 2006, p. 52). The easiest and main way to maintain this learning connection is to find the right information directly, or find the right people. Learner-content interaction and learnergroup (set and network) interaction are involved in this process. This is the beginning of social network and informational network building in the interaction space created by operation interaction. Learners can not only be involved in this process actively by creating and participating in groups and networks, but also they can take advantage of recommending technologies (such as tag cloud, likes, or recommendations). A weak and looser network is formed which makes it possible to form tighter networks and groups in sensemaking interaction. The simple connectivist learning happens at this level.

\section{Sensemaking Interaction}

Sensemaking interaction is an important stage of network formulation and connection building. Downes (2006) argued that both the knowledge of individual and knowledge of social have characteristics of networks. Sensemaking interaction is a pattern recognition, information (knowledge) seeking, and a collaborative process that includes information aggregation/sharing, discussion/negotiation, reflection, and decision making. During this process, participants bring together concepts from different domains in a novel way (Siemens, 2009), and they achieve a coherent comprehension of information and make decisions quickly. Sensemaking interaction connects nodes in a technological, social, and concept (neural) network tightly together. Learners' network identities and social presence are formed gradually by participants in these sensemaking interaction activities. This is the main process of identity forming, developing, and sharing. The learner-learner (including group, set, and network) interaction and learner-content interaction in sensemaking interaction is deeper than that of wayfinding interaction. It also sets a solid foundation for innovation interaction by using the power of the social network in information connection, sharing, filtering, and aggregation, and the advantage of collective knowledge.

\section{Innovation Interaction}

Connectivist learning relies on the active participant and artifact creation of selfdirected learners (Anderson, 2009; Downes, 2012). Innovation interaction is the most challenging and the most important interaction for learners. It is a knowledge growth process by further reflection and presentation of sensemaking results. Through innovation interaction, the scope of the other three types of interaction is also extended. 
Anderson (2012) proposed open artifact persistence and networking opportunity as the primary affordances of connectivist pedagogy. Learning artifact creation requires the deepest cognitive engagement for learners, but it brings more networking opportunities for the learners through constructing and sharing artifacts on the open network where they are both accessible and persistent. Learners gain more opportunity to communicate deeply with others and get more support from the network by sharing their artifacts. Open education resources (OER) are the most important and main learning resources used in connectivist learning, as they embody these connectivist ideals of networking, sharing, and persistence. Remixing, which means using OER to create something new or modified from an existing OER (Belshaw, 2013), is increasingly important for learners in connectivist learning. Innovation interaction is the deepest learner content interaction and deepest cognitive engagement of all four of these interaction levels.

\section{The Interrelationship of Four Levels of Interaction}

Interaction, in connectivist learning contexts, is a networked process rather than a linear one - with significant recursion. It is a circulating and transactional process (as the arrowed ring shows in Figure 4). The lower levels of interaction are the foundations of the higher ones, and each level influences the next. The lower levels support the development of higher levels, while the development of higher levels extends the need for learning at lower levels, such as in innovation interaction learners may need to further connect with different technologies, information, and people to support the remixing and learning artifact creation process. The higher the levels of interaction learners are involved in, the more cognitive engagement is required of them, which creates greater challenges for them. At the same time, the higher the levels of interaction the learners engage in, the more cognitive presence, network identity, and social presence evolves in an ever increasing network that they develop in their learning. In connectivist learning, keeping knowledge circulating and growing is the purpose of all learning activities (Siemens, 2006. p. 32) and interactions. Compared with social constructivism, innovation interaction is not the end of connectivist learning, but a new beginning of further networking and connection building with different nodes (technology, social, and concept) through sharing innovation interaction artifacts in an open and persistent network.

Connectivist learning is a process of networking and connection (Siemens, 2005b). Siemens argued that learning is the process of forming three basic networks: neural networks, concept networks, and external/social networks (Siemens, 2005b). During this interaction process, not only are these three networks created, but also the technological network that supports these interactions is created. In this article we argue that the personal learning network (PLN) (Couros, 2010) in connectivist learning is created by the simultaneous construction of a concept network, a social network, and a technology network. All interactions in connectivist learning play significant roles in different connection building and networking formulation processes. Operation interaction helps learners to build their PLE and to connect with different technologies. In this PLE, learners begin to build social and concept networks from wayfinding 
interaction while sensemaking interaction enhances and optimizes their PLN. A PLN also affords the deepest level of innovation interaction. Innovation interaction further promotes and sustains new knowledge creation and connection building, thus optimizing the PLN. So connectivist learning is a spiral knowledge creation with network creation and optimization with four levels of interaction. Learners not only build their PLN by these interactions, but also enrich the entire network as a part of a larger network of all participants.

\section{Discussion}

We divided the practice of connectivist learning into three forms (simple, social, and complex). Each of these can be explained by four levels of interaction. Simple connectivist learning is supported mainly by operational interaction and wayfinding interaction, while social networked learning is supported mainly by operation interaction, wayfinding interaction, and sensemaking interaction. Complex connectivist learning combines these four levels of interaction and is enhanced by innovation interaction. All of these interactions have different characteristics and principles which need more exploration and, indeed, the whole model currently lacks empirical validation; nonetheless, we believe that this conceptual model reduces the confusion and the multiple aims and claims associated with connectivist learning.

Even initially, connectivist learning demands basic ability and network literacy to learn in complex information environments. Learners should have a good level of digital literacy and learning literacy (Littlejohn, 2013). As they learn they develop their capacity of self-regulation, orientation, and pattern recognition and to use a variety of technologies to enhance their learning. However, many of them lack these skills and even low levels of operational interaction can be a challenge for them. Each level requires increased levels of network literacy to advance to a deeper level. The participant numbers decrease as the interaction levels become higher. Most learners are involved in the wayfinding and sensemaking levels, while fewer reach the innovation level. This explains why many people register in cMOOC courses but relatively few are actively involved in creating learning artifacts (Siemens, 2011). It also helps us to understand why interaction design in connectivist learning is important. Research and, more important, learning design are needed to design interaction and scaffolding to help learners to participate in higher level interactions in connectivist learning.

Theory building is a systematic project with five phases, and continues with refinement and development. This paper has only addressed the first and second phases. Although the framework is inspired by two pioneers of connectivism (George Siemens and Stephen Downes) and other connnectivist learning researchers, the interaction in real connectivist learning contexts, such as cMOOCs, may tell us more. Thus, research to analyse the interaction process of Change $11 \mathrm{MOOC}$ is currently in progress with the aim of validating this framework and finding the characteristics and principles of each level of interaction in this framework. 


\section{Conclusion}

This paper addresses the importance of the characteristics and principles of interaction in connectivist learning and especially those associated with the development of connectivism and cMOOCs. After a brief literature review of connectivism and its practical (simple, social, and complex) forms, the study focused on complex connectivist learning. By summarizing the types of interaction in connectivist learning, it is argued that interaction in connectivist pedagogies is complicated, thus it is challenging to gain a deep understanding of analysis interaction from the perspective of actors previously identified in the literature. However by combining the HMII model and Bloom's revised taxonomy with Siemens' elements of wayfinding and sensemaking, a framework for interaction and cognitive engagement in connectivist learning is constructed using a theory-building methodology. Interaction in connectivist learning is thus divided into four levels: operation interaction, wayfinding interaction, sensemaking interaction, and innovation interaction. From the lower to the higher levels, deeper cognitive engagement is required from the learners. All of these layers influence each other. Lower-level interactions are the foundations of the higher ones, and the higher level learners engage in deeper learning with more connection and networking opportunities.

\section{Acknowledgements}

Thanks to the Centre for Distance Education at Athabasca University for providing the environment for this research.

The paper has been updated from one presented at the 25th ICDE World Conference in Tianjin, China: A Conceptual Framework on Cognitive Engagement for Connectivist Learning: Interaction Principle based Connectivism. 


\section{References}

Anderson, L. W., Krathwohl, D. R., Airasian, P. W., Cruikshank, K. A., Mayer, R. E., Pintrich, P. R., Raths, J ., \&Wittrock, M. C. (2000). A taxonomy for learning, teaching, and assessing: A revision of Bloom's taxonomy of educational objectives. New York: Pearson, Allyn \& Bacon.

Anderson, T. (2003). Getting the mix right again: An updated and theoretical rationale for interaction. The International Review of Research in Open and Distance Learning, 4(2). Retrieved from http:// www.irrodl.org/index.php/irrodl/article/view/ 149/230.

Anderson, T. (2009, J une). The dance of technology and pedagogy in self-paced distance education. Paper presented at the 17th ICDE World Congress, Maastricht.

Anderson, T. (2012)."Connectivying" your course. Retrieved from http:/ / terrya.edublogs.org/ 2012/ 12/ 18/ connectivy-your-course/

Anderson, T., \& Dron, J . (2007). Groups, networks and collectives in social software for e-learning. Paper presented at 2007 European Conference on E-Learning, Copenhagen, Denmark.

Anderson, T., \& Dron, J . (2011). Three generations of distance education pedagogy. The International Review of Research in Open and Distance Learning, 12(3). Retrieved from http:/ / www.irrodl.org/ index.php/irrodl/ article/ view/ 890/ 1663

Anderson, T., Dron J ., Poellhuber, B., \&Upton, L. (2013, October). Beyond the learning management system to support networked distance education. Paper presentated at The $25^{\text {th }}$ ICDE World Conference, Tianjin, China.

Anderson, T., \& Garrison, D. R. (1998). Learning in a networked world: New roles and responsibilities. In C. Gibson (Ed.), Distance learners in higher education (pp. 97-112). Madison, WI.: Atwood Publishing.

Ally, M. (2004). Foundations of educational theory for online learning. In T. Anderson (Ed.), Theory and practice of online learning (1st ed., pp. 3-31). Edmonton : Athabasca University Press.

Bell, F. (2011). Connectivism: Its place in theory-informed research and innovation in technology-enabled learning. The International Review of Research in Open and Distance Learning, 12(3), 98-118.

Belshaw, D. (2013). First draft of Mozilla's web literacy standard now available. Retrieved from http:/ / dougbelshaw.com/ blog/2013/ 04/26/ first-draft-ofmozillas-web-literacy-standard-now-available/. 
Bloom, B. S. (1956). Taxonomy of educational objectives, Handbook I: The cognitive domain. New York: David McKay Co Inc.

Cheng, G., Yu, S. Q., \& Yang. X. M.(2009). Design and implementation of runtime environment for learning cells. Open Education Research, 15(2), 27-36.

Chen, L. (2004a). An investigation into 'interactivity' and the related concepts. Distance Education in China, (03), 12-16+78-79.

Chen, L. (2004b). A hierarchical model for student and teacher interaction in distance learning. Distance Education in China, (05), 24-28+78.

Chou, C., Peng, H., \& Chang, C.-Y. (2010). The technical framework of interactive functions for course-management systems: Students' perceptions, uses, and evaluations. Computers \&Education, 55(3), 1004-1017.

Clarà, M., \& Barberà, E. (2013). Three problems with the connectivist conception of learning. J ournal of Computer Assisted Learning, n/a-n/a. doi: 10.1111/jcal.12040.

Conole, G., Galley, R., \& Culver, J . (2010). Frameworks for understanding the nature of interactions, networking, and community in a social networking site for academic practice. The International Review of Research in Open and Distance Learning, 12(3). Retrieved from http:// www.irrodl.org/index.php/irrodl/article/view/ 914/ 1666.

Conrad, D. (in press). Interaction and communication in online learning communities: Toward an engaged and flexible future. In O. Zawacki-Richter \& T. Anderson (Eds.), Online distance education: Towards a research agenda. Edmonton, AB: Athabasca University Press.

Couros, A. (2010). Developing personal learning networks for open and social learning. Emerging Technologies in Distance Education, 109-128.

Downes, S. (2005). Connective knowledge. Retrieved from http:// www.downes.ca/ cgi$\underline{\text { bin/page.cgi?post }=33034}$

Downes, S. (2006). Learning networks and connective knowledge. Discussion paper \#92 (online document). Instructional Technology Forum. Retrieved from http://it.coe.uga.edu/itforum/ paper92/ paper92.html.

Downes, S. (2007). What connectivism is. Retrieved from http:/ / halfanhour.blogspot.com/ 2007/ 02/ what-connectivism-is.html 
Downes, S. (2011). How to participate in MOOC. Retrieved from http:/ / halfanhour.blogspot.com/ 2011/ 09/ how-to-participate-inmooc.html

Downes, S. (2012). Connectivism and connective knowledge: Essays on meaning and learning networks. National Research Council Canada. Retrieved from http:// www. downes. ca/files/books/Connective_Knowledge-19May2012. pdf

Dron, J . (2007). Control and constraint in e-learning: Choosing when to choose. Hershey, PA.: Information Science Pub.

Dron, J . (2013). Soft is hard and hard is easy: Learning technologies and social media. Form@ re-Open J ournal per la formazione in rete, 13(1), 32-43.

Dron, J ., \&Anderson,T., (in press). Teaching crowds: Learning and social media. Edmonton : Athabasca University Press.

Dunlap, J . C., Sobel, D., \& Sands, D. I. (2007). Designing for deep and meaningful student-to-content interactions. Tech Trends, 51(4), 20-31.

Fonseca, D. E. L. (2011). EduCamp Colombia: Social networked learning for teacher training. The International Review of Research in Open and Distance Learning, 12(3), Retrieved from http:// www.irrodl.org/index.php/irrodl/article/view/ 884/ 1677

Fadell, A. M., Rogers, M. L., Satterthwaite Jr, E. H., Smith, I. C., Warren, D. A., Palmer, J. E., . . . Fiennes, H. (2013). User-friendly network connected learning thermostat and related systems and methods. US Patent.

Garrison, D. R., \&Anderson, T. (2003). E-learning in the 21st century: A framework for research and practice. London: Routledge/ Falmer.

Granovetter, M. S. (1973). The strength of weak ties. American J ournal of Sociology, 1360-1380.

Hillman, D. C. A., Willis, D. J ., \& Gunawardena, C. N. (1994). Learner-interface interaction in distance education: An extension of contemporary models and strategies for practitioners. American J ournal of Distance Education, 8(2), 3042 .

Hirumi, A. (2002). A framework for analyzing, designing, and sequencing planned elearning interactions. Quarterly Review of Distance Education, 3(2), 141-60.

Hirumi, A. (2006). Analysing and designing e-learning interactions. In C. J uwah (Ed.), Interactions in online education: Implications for theory and practice (pp. 4671). New York: Routledge. 
Holmberg, B. (1981). Status and trends of distance education. London: Kogan-Page.

J oo, Y. J ., Lim, K. Y., \& Kim, E. K. (2011). Online university students' satisfaction and persistence: Examining perceived level of presence, usefulness and ease of use as predictors in a structural model. Computers \& Education, 57(2), 1654-1664. doi: http:// dx.doi.org/ 10.1016/j.compedu.2011.02.008.

Kauffman, S. (2000). Investigations. New York, USA: Oxford University Press.

Kay, A. (2006). The dynamics of public policy: Theory and evidence. Edward Elgar Publishing.

Keegan, D. (1993). Reintegration of the teaching acts. Theoretical Principles of Distance Education, 113-134.

Kop, R., \& Hill, A. (2008). Connectivism: Learning theory of the future or vestige of the past? The International Review of Research in Open and Distance Learning, 9(3). Retrieved from http:// www.irrodl.org/index.php/irrodl/article/ view/ 523/1103.

Laurillard, D. (2000). A conversational framework for individual learning applied to the learning organization' and the learning society'. Systems Research and Behavioral Science, 16(2), 113-122.

Littlejohn, A.(2013). Understanding massive open online course. Caledonian Academy Glasgow Caledonian University, UK.

Lynham, S. A. (2000). The development of a theory of responsibleleadership for performance (Tech. Rep.). St. Paul: University of Minnesota, Human Resource Development Research Center.

Lynham, S. A. (2002). The general method of theory-building research in applied disciplines. Advances in Developing Human Resources, 4(3), 221-241.

Mahle, M. (2011). Effects of interaction on student achievement and motivation in distance education. Quarterly Review of Distance Education, 12(3), 207215,222 .

Malliga, P. (2013). A survey on MOOC providers for higher education. International J ournal of Management \& Information Technology, 7(1), 962-967.

Martindale, T., \&Dowdy, M. (2010). Personal learning environments. Emerging Technologies in Distance Education, 177-193.

Moore, M. (1989). Three types of interaction. American J ournal of Distance Education, $3(2), 1-6$. 
Moore, M. G. (1993). Theory of transactional distance. In Theoretical principles of distance education (pp. 22- 38). London: Rutledge.

Nandi, D. (2013). A comprehensive framework with design principles for supporting interaction in fully online courses (Doctoral dissertation). Royal Melbourne Institute of Technology University .

Offir, B., Lev, Y., \& Bezalel, R. (2008). Surface and deep learning processes in distance education: Synchronous versus asynchronous systems. Computers \& Education, 51(3), 1172-1183.

Ostashewski, N., \& Reid, D. (2010). Networked teacher professional development: Applying the networked learning framework to online teacher professional development. Proceedings EDGE, 12-15.

Salmon, G. (2000). E-moderating : The key to teaching and learning online. London: Clays Ltd.

Siemens, G. (2005a). Connectivism: A learning theory for the digital age. International J ournal of Instructional Technology and Distance Learning, 2(1), 3-10.

Siemens, G. (2005b). Connectivism: Learning as network-creation. Retrieved from http:// www.elearnspace.org/ Articles/networks.htm.

Siemens, G. (2006). Knowing knowledge. Lulu. com.

Siemens, G. (2009). What is connectivism? Retrieved from https:// docs.google.com/ document/d/ 14pKVP0_ILdPty6MGMJ W8eQVE Y1zibZ0RpQ2C0cePIgc/ preview

Siemens, G. (2011). Orientation: Sensemaking and wayfinding in complex distributed online information environments (Doctoral dissertation). University of Aberdeen.

Siemens, G., \& Conole, G. (2011). Special issue-Connectivism: Design and delivery of social networked learning. International Review of Research in Open and Distance Learning, 12(3). Retrieved from http:// www.irrodl.org/index.php/ irrodl/issue/view/ 44

Sewart, D., Keegan, D., \& Holmberg, B. (Eds.) (1983). Distance education: International perspectives. London: Croom Helm.

So, H. (2010). Towards rigor of online interaction research: Implication for future distance learning research. The Turkish Online J ournal of Educational Technology, 9(2), 256-263. 
Sun, H. T.(2013). Social affordance of typical Web 2.0 tools in distance education (Doctoral dissertation). Beijing Normal University.

Taylor, J . C. (2001). Fifth generation distance education. Retrieved from http:// www.usq.edu.au/ users/taylorj/ conferences.htm

Tello, S. F. (2007). An analysis of student persistence in online education. International J ournal of Information and Communication Technology Education, 3(3), 4762.

Verhagen, P. (2006). Connectivism: A new learning theory? Surf e-learning themasite. Retrieved from http:// elearning.surf.nl/e-learning/english/3793

Wagner, E. D. (1994). In support of a functional definition of interaction. The American J ournal of Distance Education, 8(2), 6-26.

Wang, Z.J .(2013). A new perspective of instructional interaction research in distance education: Structuralism. Morden Distance Education Research, 5, 28-33.

Wen-chi, V. W., Yen, L. L., \& Marek, M. (2011). Using online EFL interaction to increase confidence, motivation, and ability. J ournal of Educational Technology \& Society, 14(3), 118-n/a.

Woo, Y., \& Reeves, T. C. (2007). Meaningful interaction in web-based learning: A social constructivist interpretation. The Internet and Higher Education, 10(1), 15-25.

\section{Athabasca University $\mathbf{Z}$}

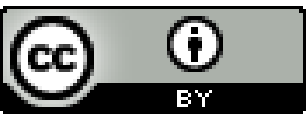

